\title{
Modeling of the thermoregulation system in the skunk cabbage: Symplocarpus foetidus
}

\author{
Ken Takahashi, ${ }^{1,2, *}$ Takanori Ito, ${ }^{1}$ Yoshihiko Onda, ${ }^{3}$ Takehiro Endo, ${ }^{1, \dagger}$ Shigeki Chiba, ${ }^{1}$ Kikukatsu Ito, ${ }^{3, \ddagger}$ and Hiroshi Osada ${ }^{1, \S}$ \\ ${ }^{1}$ Department of Electrical and Electronic Engineering, Faculty of Engineering, Iwate University, \\ 4-3-5, Ueda, Morioka, Iwate 020-8551, Japan \\ ${ }^{2}$ Daisho Denshi Co., Ltd., 1-26-2, Tairamachi, Meguro-ku, Tokyo 152-0032, Japan \\ ${ }^{3}$ Cryobiosystem Research Center, Faculty of Agriculture, Iwate University, 3-18-8, Ueda, Morioka, Iwate 020-8550, Japan
}

(Received 31 January 2007; revised manuscript received 21 May 2007; published 18 September 2007)

\begin{abstract}
This paper presents a model of the thermoregulation system of the spadix of skunk cabbage Symplocarpus foetidus which regulates its internal temperature at around $20{ }^{\circ} \mathrm{C}$ during flowering even when the ambient air temperature drops below freezing. From the temperature responses of the spadix to changing ambient air temperature, we assumed that the thermoregulation system of the spadix is probably one of negative feedback control. The feedback signals are based on the rate of temperature change of the spadix over time. A signal is factored into the biochemical energy generator, and becomes biochemical energy, some of which becomes heat. Comparing our proposed model temperature responses and those of the living spadix, we found good agreement. In the process of engineering the model, the existence of two regulatory pathways in the thermoregulation system was simulated, and our proposed model appears to provide the necessary elements to explain the fundamental mechanism of the thermoregulation system of $S$. foetidus.
\end{abstract}

DOI: 10.1103/PhysRevE.76.031918

PACS number(s): 87.80.Vt, 07.05.Dz, 07.07.Tw

\section{INTRODUCTION}

Plants are generally recognized as poikilothermic organisms because they are usually not capable of controlling their own temperatures by generating heat. Thermogenesis is an interesting phenomenon in which the temperature of a flower increases by the flower producing its own heat. The skunk cabbage Symplocarpus foetidus, which belongs to the Arum family, is a thermogenic plant that blooms in early spring, and regulates the internal temperature of its spadix to be around $20^{\circ} \mathrm{C}$ even when the ambient air temperature drops below freezing [1-8]. The thermogenic period in $S$. foetidus was determined to be a week or more in length [1-3]. The role of thermogenesis is generally assumed to enhance vaporization of the floral scent [9]. This may be the situation for S. foetidus which produces a faint, sweet aroma (if the flower is undamaged), but heating may also enable early flowering, protect the inflorescence from damage by freezing, or provide a warm environment for invertebrate visitors [1-3].

In recent years, a number of studies have explored the mechanism involved in temperature regulation in the spadix of S. foetidus. Knutson's temperature recordings of the spadix [2] revealed that the spadix achieved temperatures as high as $20^{\circ} \mathrm{C}$ at ambient air temperatures as low as $-14{ }^{\circ} \mathrm{C}$. The mechanism of temperature regulation resides in the spadix tissue alone, not in the spathe, leaves or spadix stalk [7]. $S$. foetidus has a sensitive thermoregulation mechanism that responds to temperature changes as small as $\pm 0.9{ }^{\circ} \mathrm{C}$ / $30 \mathrm{~min}[7,8]$. The temperature of the spadix has a transient

\footnotetext{
*t5306004@iwate-u.ac.jp

${ }^{\dagger}$ Present address: Honda Motor Co., Ltd., 2-1-1, Aoyama, Minatoku, Tokyo 107-8556, Japan.

*kikuito@iwate-u.ac.jp

§osada@iwate-u.ac.jp
}

oscillation of about 60 min per cycle [8]. Although the precise mechanism of temperature regulation in $S$. foetidus has not been elucidated, the dynamics of thermoregulatory responses in $S$. foetidus have been described from the biochemical aspect [10]. Moreover, Ito et al. [11,12] have reported on the dynamics of temperature control in S. foetidus using nonlinear forecasting, attractors and correlation dimension analyses. From their results, it have been shown that thermoregulation in $S$. foetidus is governed by low-dimensional nonlinear dynamics with the unique attractor named the "Zazen attractor."

More recently, control mechanisms of living organisms, such as the thermoregulation system in the spadix of $S$. foetidus, have attracted much research interest, and have been recognized as important examples of bioengineering technology; for example, an amphibious snakelike robot [13] and a biomimetic walking SCORPION robot [14]. Furthermore, Yi et al. have studied the control mechanism of a bacterial chemotaxis by the approach of the systems biology [15].

In this paper, we report the development of an engineering model for the thermoregulation system in the spadix of $S$. foetidus. The response of our proposed model to temperature changes of the surrounding has been consistent with actual temperature responses in S. foetidus, which includes both heat production and temperature detection. It is, thus, implied that this simple model could represent the dynamical system for thermoregulation in the spadix of $S$. foetidus.

\section{MATERIALS AND METHODS}

\section{A. Plant materials and temperature measurements}

S. foetidus plants were transferred from the field to the laboratory and placed in a temperature-controlled growth chamber (Fig. 1), and the temperature of the spadix was recorded at $1 \mathrm{~min}$ intervals using an automatic recording thermometer connected to a thermistor (TR-52, T\&D, Inc., Na- 


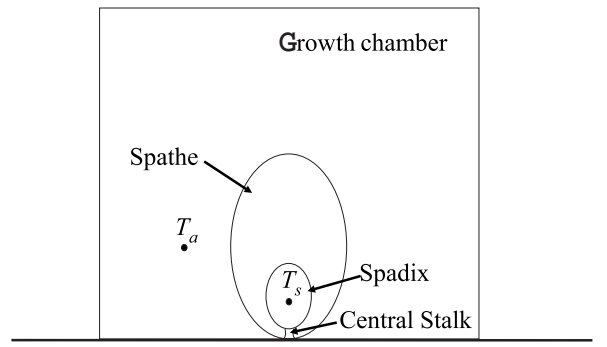

FIG. 1. Ambient air temperature $\left(T_{a}\right)$ and spadix temperature $\left(T_{s}\right)$ were measured with thermistor thermometry at the indicated locations.

gano, Japan) placed on the surface of the spadix. The air temperature was also measured using the same thermometer.

\section{B. Measurements of thermal properties of the spadix of $S$. foetidus}

The thermal conductivity $(\lambda)$ and thermal diffusivity $(\alpha)$ of the spadix were recorded using a thermal properties analyzer (KD2, Decagon Devices, Inc., USA). The analyzer employs a single needle sensor to measure thermal properties using a transient heat-pulse methodology [16]. In this method a heat pulse is applied to a line source, and the temperature response at the line source or at some distance from the line source is analyzed [17].

The spadices were decapitated using stainless-steel razor blades, and the needle sensor was inserted into them. The values which were obtained were expressed as the mean $\pm S D$.

\section{Measurements of the heat transfer coefficient between the spadix of $S$. foetidus and the ambient air}

The heat transfer coefficient between the spadix of $S$. foetidus and the ambient air was determined from the results of experiments to determine the cooling curve of the spadix. The spadices were decapitated using stainless-steel razor blades and placed in a temperature-controlled bath. They were subjected to a set of ambient temperature shifts which were programed to change from $20^{\circ} \mathrm{C} \rightarrow 15^{\circ} \mathrm{C}$. The tem- perature of the spadices and ambient air were recorded at 1 min intervals using an automatic recording thermometer. The heat transfer coefficient between the spadix of S. foetidus and the ambient air can be calculated using the following equation [18]:

$$
\frac{d T_{s}}{d t}=-\frac{h}{C}\left(T_{s}-T_{a}\right),
$$

where $T_{s}$ is the temperature of the spadix, $T_{a}$ is the ambient air temperature, and $h$ is the heat transfer coefficient between the spadix of $S$. foetidus and the ambient air. $C$ is the thermal capacity of the spadix, and is calculated from the spadix mass $(m)$ and the specific heat capacity of the spadix $(c)$ :

$$
C=m c .
$$

$c$ is calculated using the following equation:

$$
c=\frac{\lambda}{\alpha \rho},
$$

where $\lambda, \alpha$, and $\rho$ are the thermal conductivity, thermal diffusivity, and density of the spadix, respectively.

The cubic volumes of the spadices $(V)$ were calculated under the assumption that the shape of the spadix is an ellipsoid. The values which were obtained were expressed as the mean $\pm S D$.

\section{THE THERMOREGULATION SYSTEM OF THE SPADIX OF $S$. FOETIDUS}

Figure 2(a) shows the temperature response of the spadix of $S$. foetidus $\left(T_{s}\right)$ when the ambient air temperature $\left(T_{a}\right)$ was changed rapidly (the changing air temperature gradient was $\left.0.5-1{ }^{\circ} \mathrm{C} / \mathrm{min}\right)$. At first $T_{s}$ changed with $T_{a}$, but then it slowly recovered nearly to the original level. It was also observed that the recovery time for the spadix temperature had a period of around $58 \mathrm{~min}$.

In contrast, the response of the spadix to a gradual ambient air temperature change $\left(0.013{ }^{\circ} \mathrm{C} / \mathrm{min}\right)$ was quite different [Fig. 2(b)]. $T_{s}$ decreased continuously with $T_{a}$, and failed to respond to the decrease in $T_{s}\left(1.3{ }^{\circ} \mathrm{C}\right)$, which was a temperature differential that was greater than the sensitivity of (a)

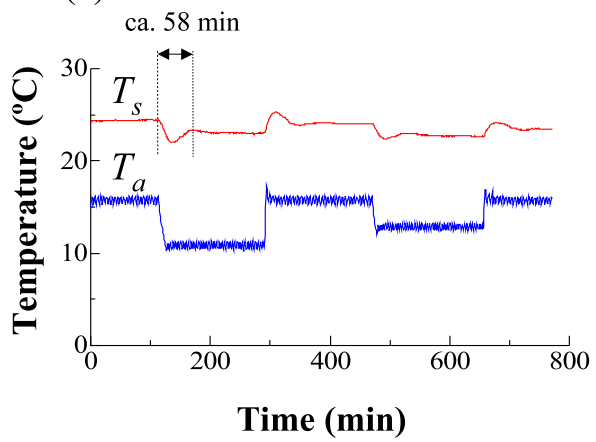

(b)

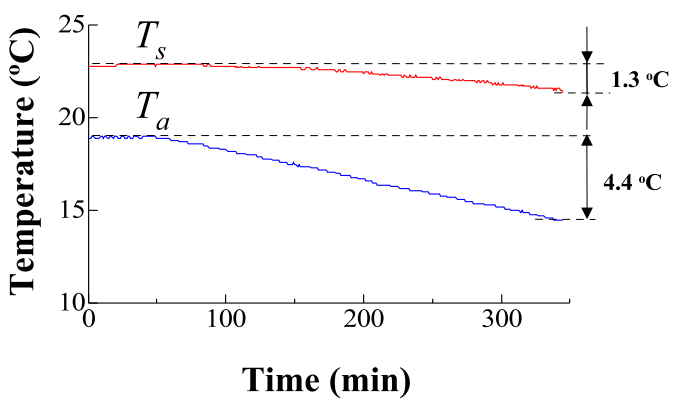

FIG. 2. (Color online) Temperature responses of the spadix $\left(T_{s}\right)$ to the external air temperatures $\left(T_{a}\right)$. The air temperature was changed quickly (a) and gradually (b). 


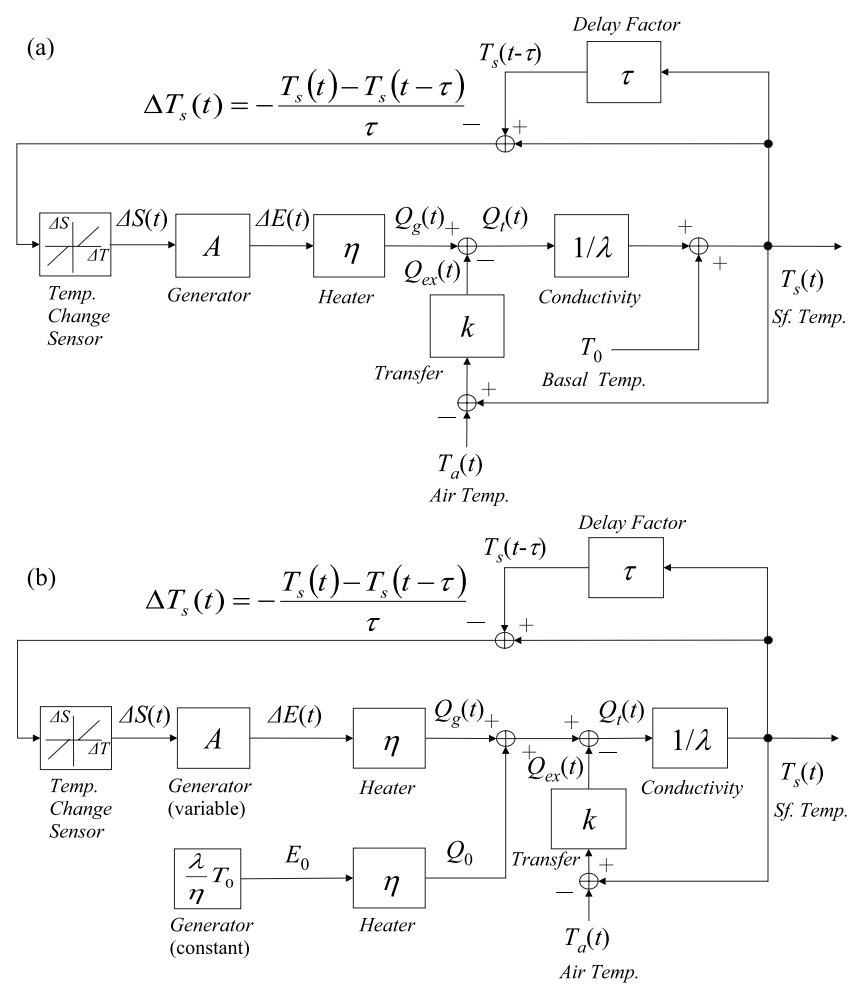

FIG. 3. Two equivalent expressions of our proposed thermoregulation model of the spadix of $S$. foetidus.

the internal temperature-change sensor of the spadix $\left( \pm 0.9^{\circ} \mathrm{C} / 30 \mathrm{~min}\right)[7,8]$.

Based on these results, it is hypothesized that negative feedback controls the thermoregulation found in the spadix. The control system is triggered when a temperature variation of the spadix exceeds a certain threshold value within a certain time interval. Thus, the thermoregulation system is not a type of proportional control, which is proportional to the difference between a setting and the present temperature, but rather a derivative control, which is proportional to the temporal change in the temperature of the spadix.

\section{A MODEL OF THERMOREGULATION OF THE SPADIX OF $S$. FOETIDUS}

Our proposed model of the thermoregulation system of the spadix of $S$. foetidus is shown in Fig. 3(a). The controller in this system is constructed of two elements, the generator and the heater.

Variation in the temperature of the spadix $\left(\Delta T_{s}\right)$ in the company of a delay time $(\tau)$ is defined as follows:

$$
\Delta T_{s}(t)=-\frac{T_{s}(t)-T_{s}(t-\tau)}{\tau},
$$

where $T_{s}(t)$ is the present temperature of spadix, and $T_{s}(t$ $-\tau)$ is the temperature of the spadix before $\tau$.

$\Delta T_{s}$ is transformed to a negative feedback signal $\Delta S$ by the temperature-change sensor, which detects the temperature change of the spadix and has a certain sensitivity (width
TABLE I. Parameters of the thermoregulation model of the spadix of S. foetidus.

\begin{tabular}{cc}
\hline \hline Symbol & Value \\
\hline$\tau(\min )$ & 3 \\
$k\left(\mathrm{~W} / \mathrm{m}^{2} \mathrm{~K}\right)$ & 0.3 \\
$\eta$ & 0.2 \\
$\lambda(\mathrm{W} / \mathrm{mK})$ & 0.33 \\
$A$ & 1.0 \\
$E_{0}(\mathrm{~W} \mathrm{~s})$ & 40 \\
\hline
\end{tabular}

of the dead zone $\pm 0.9^{\circ} \mathrm{C}$ ). If $\Delta T_{s}$ is greater than the dead zone of the sensor, then $\Delta T_{s} \approx \Delta S$.

$\Delta S$ is factored into the biochemical energy generator (generator), and becomes biochemical energy $(\Delta E)$ as follows:

$$
\Delta E(t)=A \Delta S(t) \approx A \Delta T_{s}(t),
$$

where $A$ is an effective parameter summarizing unknown process that probably include feedback.

A part of the biochemical energy becomes heat:

$$
Q_{g}(t)=\eta \Delta E(t),
$$

where $Q_{g}$ is the generated heat and $\eta$ is the efficiency of the energy conversion between $\Delta E$ and $Q_{g}$. The heat of convection between the spadix and the ambient air $\left(Q_{\mathrm{ex}}\right)$ is proportional to the difference between the temperature of the spadix and the ambient air temperature, according to Newton's cooling law:

$$
Q_{\mathrm{ex}}(t)=k\left[T_{s}(t)-T_{a}(t)\right]
$$

where $k$ is a constant which is proportional to the heat transfer coefficient and to time over which the heat transfer occurs.

The total variation of heat $\left(Q_{t}\right)$ is described as follows:

$$
Q_{t}(t)=Q_{g}(t)-Q_{\mathrm{ex}}(t) .
$$

The temperature of the spadix can be represented with the following equation:

$$
T_{s}(t)=T_{0}+\frac{1}{\lambda} Q_{t}(t)
$$

where $T_{0}$ is the basal temperature of the spadix and $\lambda$ is the thermal conductivity of the spadix. Thus, the thermoregulation system of the spadix is described as follows:

$$
T_{s}(t)=T_{0}+\frac{1}{\lambda}\left[\eta A \Delta T_{s}(t)-Q_{\mathrm{ex}}(t)\right] .
$$

On the other hand, the basal energy $\left(E_{0}=\frac{\lambda}{\eta} T_{0}\right)$ is defined as the energy which is used to generate and maintain $T_{0}$, so that Fig. 3(a) can be expressed as Fig. 3(b), and the thermoregulation system can be described by the following equation: 


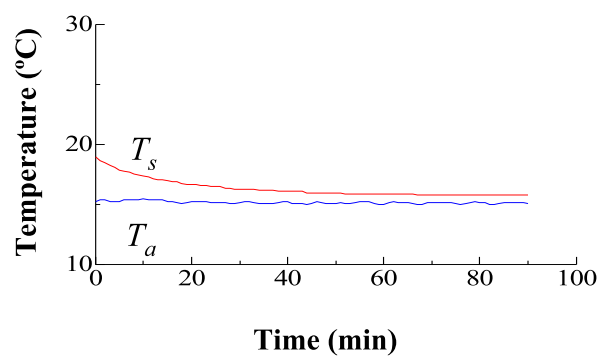

FIG. 4. (Color online) A typical cooling curve of the spadix of $S$. foetidus $\left(T_{s}\right)$ and the external air temperature $\left(T_{a}\right)$.

$$
\begin{aligned}
T_{s}(t) & =\frac{1}{\lambda}\left[\eta\left(A \Delta T_{s}(t)+E_{0}\right)-Q_{\mathrm{ex}}(t)\right] \\
& =\frac{1}{\lambda}\left[\eta\left(\Delta E(t)+E_{0}\right)-Q_{\mathrm{ex}}(t)\right] .
\end{aligned}
$$

Here, $Q_{\text {ex }}$ is not the object of control in Eq. (11). There are two factors which control the temperature of the spadix, the variation of the basal energy $\Delta E$, which is related to $\Delta T_{s}$, and the basal energy $E_{0}$, which is used to generate and maintain $T_{0}$. The initial conditions for Eq. (11) are presented as

$$
T_{s}(0)=T_{0} \text {. }
$$

\section{VALIDATION OF THE MODEL OF THERMOREGULATION SYSTEM OF THE SPADIX OF S. FOETIDUS}

To validate the proposed model, the results of simulations using the model [Eq. (11)] were compared with experimental temperature data of the spadix of $S$. foetidus. Table I shows the values of the coefficients in Eq. (11), which were determined in the following manner. $A$ was determined under the assumption that the negative feedback signal $\Delta S$ is transmitted directly from the temperature-change sensor to the generator. Thus, $A$ was estimated to be about 1.0. $\eta$ and $\tau$ were determined by using trial and error so that our proposed model temperature responses and those of the living spadix are matched. $k$ was determined from the results of experi-
TABLE II. Morphology and thermal properties of the spadix of S. foetidus.

\begin{tabular}{cc}
\hline \hline Symbol & Value \\
\hline$m(\mathrm{~g})$ & $3.59 \pm 0.32$ \\
$V\left(\mathrm{~cm}^{3}\right)$ & $2.25 \pm 0.43$ \\
$\rho\left(\mathrm{g} / \mathrm{cm}^{3}\right)$ & $1.69 \pm 0.47$ \\
$\alpha\left(\mathrm{mm}^{2} / \mathrm{s}\right)$ & $0.126 \pm 0.073$ \\
$c(\mathrm{~J} / \mathrm{g} \mathrm{K})$ & $1.66 \pm 0.46$ \\
$C(\mathrm{~J} / \mathrm{K})$ & $5.80 \pm 1.12$ \\
\hline
\end{tabular}

ments to determine the cooling curve of the spadix. Typical data are shown in Fig. 4. Table II shows the morphology and thermal properties of the spadix. $\lambda$ was recorded using a thermal properties analyzer. $E_{0}$, which maintains the basal temperature of the spadix (about $20^{\circ} \mathrm{C}$ ), was determined using trial and error.

Here, we studied the effects of varying $A$ and $\tau$ on the control response. Any increase (or decrease) in the value of $\tau$ increased (or decreased) the period of recovery time of the temperature of the spadix, and any increase (or decrease) in $A$ improved (or deteriorated) the control performance of the thermoregulation system.

Our proposed model has been implemented using MATLAB/SIMULINK (Math Works, Inc., MA, USA). Figure 5(a) shows the temperatures calculated by the model when the ambient air temperature is changed rapidly $\left(16^{\circ} \mathrm{C}\right.$ $\left.\rightarrow 11^{\circ} \mathrm{C} \rightarrow 16^{\circ} \mathrm{C} \rightarrow 13{ }^{\circ} \mathrm{C} \rightarrow 16^{\circ} \mathrm{C}\right)$. Comparing the simulation results of the model in Fig. 5(a) to empirical results of the spadix in Fig. 2(a), these temperature responses were in good agreement with each other. In addition, the recovery time (about $58 \mathrm{~min}$ ) present in the spadix was well simulated by the model. The temperature response of the spadix in our model when the ambient air temperature was decreased gradually from 19 to $14.5^{\circ} \mathrm{C}$ is shown in Fig. 5(b). The temperature of the spadix $\left(T_{s}\right)$ decreases with decreasing ambient air temperature. The drop of $T_{s}$ is $1.3{ }^{\circ} \mathrm{C}$, after a lapse $340 \mathrm{~min}$. The same result was obtained by the experiment with the living plant [Fig. 2(b)]. (a)

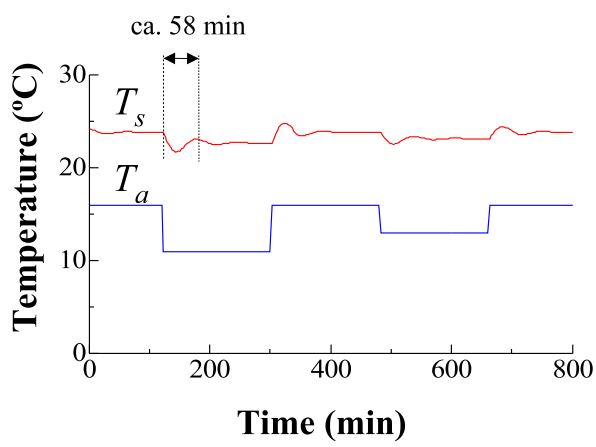

(b)

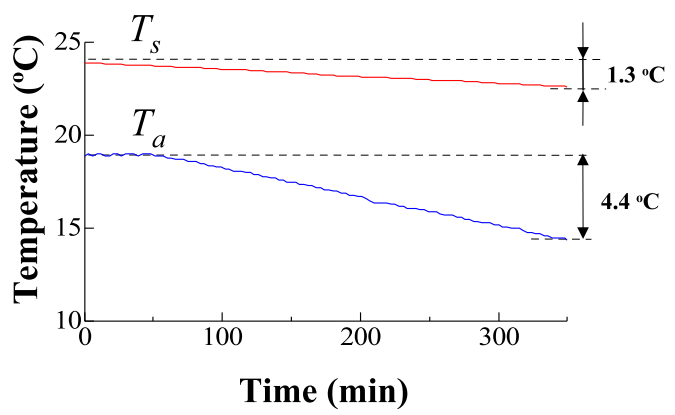

FIG. 5. (Color online) Temperature responses of the thermoregulation model of the spadix of S. foetidus $\left(T_{s}\right)$ to the external air temperature $\left(T_{a}\right)$. The air temperature was changed quickly (a) and gradually (b). 


\section{DISCUSSION}

In this study, we developed a model of the thermoregulation system for the spadix of $S$. foetidus. The output of the proposed model has been compared to empirical results with the plant under different conditions (Figs. 2 and 5), and it has provided acceptable results. Our proposed model appears to provide the necessary elements to explain the fundamental mechanism of the thermoregulation system of $S$. foetidus. The heater in the proposed model was constructed with $Q_{g}$ and $Q_{0}$ using an engineering approach, and had two regulatory pathways.

In previous studies, oxygen consumption during flowering has been shown to increase during heat production $[2,6]$. Because recent work has reported that carbohydrates are used as major substrates for thermogenesis in $S$. foetidus [19], it has been suggested that metabolic pathways, including glycolysis, the TCA cycle, and the mitochondrial electron transport chain, act as such regulatory modules that potentially react with the change of the spadix temperature [20]. Especially, it would be of particular interest to note that the cyanide-insensitive alternative oxidase (AOX) [21-26] and the species-specific uncoupling protein (UCP) [27-30], both of which are located in the mitochondrial inner membrane, act as central thermogenic modules within a cell. Therefore, it is probable that $Q_{0}$ and $Q_{g}$ in our proposed model are regulatory pathways that (1) generate biochemical energy such as reduced nicotinamide adenine dinucleotide (NADH) during the glycolysis in cytosol, and (2) convert the biochemical energy into heat in the mitochondria that both AOX and UCP molecules are located in.
To obtain the variation of the temperature of the spadix of $S$. foetidus $\Delta T_{s}$, it is necessary for the plant to keep track of the initial temperature $\tau, T_{s}(t-\tau)$ [see Eq. (4)]. Possible causes of the delay time $\left(\Delta T_{s}\right)$ in the spadix might be the diffusion of heat in the tissue, transport delay, and/or the spread of heat in the tissue. The cause or mechanism of this factor as related to time $\left(\Delta T_{s}\right)$ has yet to be sufficiently clarified, which largely depends upon future multilateral studies. To shed light on such a thermoregulation system in S. foeti$d u s$, it would be required that many biological experiments and theoretical studies, including computational simulations be performed effectively [31].

\section{ACKNOWLEDGMENTS}

The authors would like to thank M. Hara, R. Torisu, T. Hiroma, M. Uemura, and N. Tayama for their useful suggestions and encouragement. We are grateful to Yasuko ItoInaba, Kazuyoshi Kamikawa, Yasuhumi Ota, Masaki Ito, and Yoshinori Hujisawa for their valuable discussions of this work. This research was supported by the Program for Promotion of Basic Research Activities for Innovative Bioscience (PROBRAIN), by a Grant-in-Aid for the 21st Century COE program from the Ministry of Education, Culture, Sports, Science and Technology of Japan and by the New Energy and Industrial Technology Development Organization (NEDO) under the sponsorship of the Ministry of Economy, Trade and Industry (METI) of Japan.
[1] R. M. Knutson, Am. J. Bot. 88, 251 (1972).

[2] R. M. Knutson, Science 186, 746 (1974).

[3] R. M. Knutson, Nat. Hist. 88, 42 (1979).

[4] S. Uemura, K. Ohkawara, G. Kudo, N. Wada, and S. Higashi, Am. J. Bot. 80, 635 (1993).

[5] R. S. Seymour and P. Schultze-Motel, Endeavour 21, 125 (1997).

[6] R. S. Seymour and A. J. Blaylock, J. Exp. Bot. 50, 1525 (1999).

[7] K. Ito, Y. Onda, T. Sato, Y. Abe, and M. Uemura, Plant, Cell Environ. 26, 783 (2003).

[8] K. Ito, T. Ito, Y. Onda, and M. Uemura, Plant Cell Physiol. 45, 257 (2004).

[9] B. J. D. Meeuse and I. Raskin, Sex. Plant Reprod. 1, 3 (1988).

[10] R. S. Seymour, Plant, Cell Environ. 27, 1014 (2004).

[11] T. Ito and K. Ito, Phys. Rev. E 72, 051909 (2005).

[12] T. Ito, K. Ito, and Y. Ito, KASEAEE 44, 225 (2006).

[13] A. Crespi, A. Badertscher, A. Guibnard, and A. J. Ijspeert, Rob. Auton. Syst. 50, 163 (2005).

[14] B. Klaassen, R. Linnemann, D. Spenneberg, and F. Kirchner, Rob. Auton. Syst. 41, 69 (2002).

[15] T. M. Yi, Y. Huang, M. I. Simon, and J. Doule, Proc. Natl. Acad. Sci. U.S.A. 97, 4649 (2000).

[16] S. A. Taylor and C. G. Haugh, Trans. ASAE 17, 56 (1974).

[17] G. S. Campbell, C. Calissendorff, and J. H. Williams, Soil Sci. Soc. Am. J. 58, 1288 (1991).
[18] F. P. Incroperra and D. P. DeWitt, Fundamentals of Heat and Mass Transfer (Wiley, New York, 1996).

[19] K. Ito and R. S. Seymour, Cell. Mol. Biol. Lett. 1, 427 (2005).

[20] Y. Onda and K. Ito, Biosci., Biotechnol., Biochem. 69, 1156 (2005).

[21] D. A. Berthold and J. N. Seidow, Plant Physiol. 101, 113 (1993).

[22] L. McIntosh, Plant Physiol. 105, 781 (1994).

[23] D. A. Day and J. T. Wiskich, J. Bioeng. 27, 379 (1995).

[24] M. Wagner and K. Krab, Physiol. Plant. 95, 318 (1995).

[25] L. Moore, M. S. Albury, P. G. Crichton, and C. Affourtit, Trends Plant Sci. 17, 478 (2002).

[26] M. Clifton, A. H. Millar, and J. Whelan, Biochim. Biophys. Acta 1757, 730 (2006).

[27] K. Ito, Can. J. Plant Sci. 149, 167 (1999).

[28] D. G. Nicholls and R. M. Locke, Physiol. Rev. 64, 1 (1984).

[29] C. Fleury, M. Neverova, S. Collins, S. Raimbault, O. Champigny, C. Levi-Meyrueis, F. Bouillaud, M. F. Seldin, R. S. Surwit, D. Ricquier, and C. H. Warden, Nat. Genet. 15, 269 (1997).

[30] O. Boss, S. Samec, A. Paolonia-Giacobino, C. Rossier, A. Dulloo, J. Seydoux, P. Muzzin, and J. P. Giacobino, FEBS Lett. 408, 39 (1997).

[31] Y. Onda, Y. Kato, Y. Abe, T. Ito, Y. Ito-Inaba, M. Morohashi, Y. Ito, M. Ichikawa, K. Matsukawa, Y. Kakizaki, H. Koiwa, and K. Ito (unpublished). 